\title{
HEDL-7484
}

\section{SOLID-STATE TRACK RECORDER NEUTRON DOSIMETRY IN THE THREE-MILE ISLAND UNIT-2 REACTOR CAVITY}

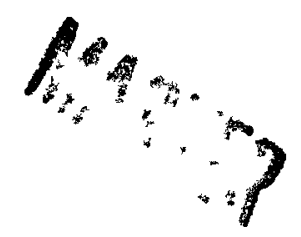

\section{DO NOT MICROFILM COVER}




\section{HZAOJ WาIJOYJIW ION 00}

Operated by

Westinghouse

A Subsidiary of

Hanford Company

Westinghouse Electric

for the U.S. DOE

Corporation

Contract No.

P.O. Box 1970

DE.AC06-76FF02170

Richland, WA 99352

\section{Hanford Engineering Development Laboratory}

\section{INFORMATION CONCERNING USE OF THIS DOCUMENT}

\section{NOTICE}

This report was prepared as an account of work sponsored by an agency of the United States Government. Neither the United States Government nor any agency thereof, nor any of their employes, nor any of their contractors, subcontractors or their employes, makes any warranty, express or implied, or assumes any legal liability or responsibility for the accuracy, completeness, or any third party's use or the result of such use of any information, apparatus, product, or process disclosed, or represents that its use would not infringe privately owned rights. Reference herein to any specific commercial product, process, or service by trade name, trademark, manufacturer, or otherwise, does not necessarily constitute or imply its endorsement, recommendation, or favoring by the United States Government or any agency thereof or its contractors or subcontractors. 


\section{DISCLAIMER}

This report was prepared as an account of work sponsored by an agency of the United States Government. Neither the United States Government nor any agency Thereof, nor any of their employees, makes any warranty, express or implied, or assumes any legal liability or responsibility for the accuracy, completeness, or usefulness of any information, apparatus, product, or process disclosed, or represents that its use would not infringe privately owned rights. Reference herein to any specific commercial product, process, or service by trade name, trademark, manufacturer, or otherwise does not necessarily constitute or imply its endorsement, recommendation, or favoring by the United States Government or any agency thereof. The views and opinions of authors expressed herein do not necessarily state or reflect those of the United States Government or any agency thereof. 


\section{DISCLAIMER}

Portions of this document may be illegible in electronic image products. Images are produced from the best available original document. 
HEDL-7484

HEDL --7484

DE85 011360

\title{
SOLID-STATE TRACK RECORDER NEUTRON DOSIMETRY IN THE THREE-MILE ISLAND UNIT-2 REACTOR CAVITY
}

\author{
DISCLAIMER
}

This report was prepared as an account of work sponsored by an agency of the United States Government. Neither the United States Government nor any agency thereof, nor any of their employees, makes any warranty, express or implied, or assumes any legal liability or responsibility for the accuracy, completeness, or usefulness of any information, apparatus, product, or process disclosed, or represents that its use would not infringe privately owned rights. Reference herein to any specific commercial product, process, or service by trade name, trademark, manufacturer, or otherwise does not necessarily constitute or imply its endorsement, recommendation, or favoring by the United States Government or any agency thereof. The views and opinions of authors expressed herein do not necessarily state or reflect those of the United States Government or any agency thereof.

\section{Raymond Gold \\ James H. Roberts \\ Frank H. Ruddy \\ Christopher C. Preston \\ William N. McElroy}

November 1984

\author{
Date of Issue: \\ April 1985
}




\section{CONTENTS}

Figures

Page

Tables

iv

iv

T.0 SUMMARY

1

2.0

INTRODUCTION

3.0 SSTR EXPERIMENT IN THE TMI-2 REACTOR CAVITY

4.0 SSTR EXPERIMENTAL RESULTS

5.0 ANALYSIS AND INTERPRETATION OF SSTR DATA

12

5.1 DETERMINATION OF ABSOLUTE THERMAL NEUTRON FLUX

12

5.2 NEUTRON STREAMING INTERPRETATION OF SSTR DATA

5.3 LOWER BOUND ESTIMATE OF THE FUEL MASS AT THE BOTTOM OF THE TMI-2 REACTOR VESSEL

6.0

ACKNOWLEDGMENTS

23

7.0

REFERENCES

24 


\section{FIGURES}

Figure

Page

1 Geometrical Details of the SSTR Neutron Dosimeter Used in the TMI-2 Annular Gap

2 Deployment of SSTR Neutron Dosimeters on an Axial

Stringer in the TMI-2 Annular Gap

3 Location of Two SSTR Stringers, East (E-SSTR) and West (W-SSTR), in the TMI-2 Annular Gap

4 Bare SSTR Track Density as a Function of Elevation in the TMI-2 Annular Gap

5 Cadmium-Covered SSTR Track Density as a Function of Elevation in the TMI-2 Annular Gap

6 Cadmium Ratio as a Function of Elevation in the TMI-2 Annular Gap

7 Thermal Neutron Fluxes in the TMI-2 Annular Gap

8 Axial Schematic of the TMI -2 Reactor Cavity

\section{TABLES}

Table

Page

1 Irradiation Test Plan

2 TMI -2 Annular Gap E-SSTR Track Density Results

3 TMI-2 Annular Gap W-SSTR Track Density Results

4 Absolute Thermal Neutron Fluxes in the TMI-2

Reactor Cavity

$5 \quad$ Neutron Transport Scale Factors 


\section{SOLID-STATE TRACK RECORDER (SSTR) NEUTRON DOSIMETRY IN THE \\ THREE-MILE ISLAND UNIT-2 (TMI-2) REACTOR CAVITY}

Raymond Gold, James H. Roberts, Frank H. Ruddy, Christopher C. Preston and William N. McElroy

\section{$1.0 \quad$ SUMMARY}

Solid-state track recorder (SSTR) neutron dosimetry has been conducted in the Three-Mile Island Unit (TMI-2) reactor cavity (i.e., the annular gap between the pressure vessel and the biological shield) for nondestructive assessment of the fuel distribution. Two axial stringers were deployed in the annular gap with 17 SSTR dosimeters located on each stringer. SSTR experimental results reveal that neutron streaming, upward from the bottom of the reactor cavity region, dominates the observed neutron intensity. These absolute thermal neutron flux observations are consistent with the presence of a significant amount of fuel debris lying at the bottom of the reactor vessel. A conservative lower bound estimated from these SSTR data implies that there is at least 2 tonnes of fuel, which is roughly 4 fuel assemblies, at the bottom of the vessel. The existence of significant neutron streaming also explains the high count rate observed with the source range monitors (SRMS) that are located in the TMI-2 reactor cavity. 


\section{$2.0 \quad$ INTRODUCTION}

Recent data at TMI-2 indicate that the void in the upper core region is substantial and that much of the displaced fuel appears to have been reduced to rubble. It is possible that significant amounts of this fuel debris have been relocated out of the core boundaries into off-normal locations. Location of fuel material is important in planning recovery operations for the TMI-2 facility.

TMI-2 fuel distribution assessments can be carried out nondestructively by gamma-ray and neutron dosimetry. In gamma-ray dosimetry, gamma-rays associated with specific fission products are measured. In neutron dosimetry, neutrons generated from a combination of spontaneous fission, $(\alpha, n)$ reactions, and subcritical multiplication are measured.

Existing constraints preclude the application of many routine dosimetry methods for TMI-2 fuel distribution characterization. These constraints have many origins, ranging from sensitivity and background considerations to practical day-to-day restrictions of TMI-2 recovery operations. Several methods have been applied to overcome these constraints, including SSTR neutron dosimetry and continuous gamma-ray spectrometry with a $\mathrm{Si}(\mathrm{Li})$ Compton spectrometer that were used to quantify the fuel debris in the TMI-2 demineralizers. A general exposition on the applicability of SSTR neutron dosimetry for TMI-2 applications has already been published. (1) Efforts to characterize the fuel distribution in the TMI-2 makeup and the purification demineralizers with SSTR neutron dosimetry and Si(Li) gamma-ray spectrometry have been successfully completed. $(2-6)$

A description of the SSTR experiment in the TMI-2 annular gap is given in Section 3.0, the experimental results are reported in Section 4.0, and Section 5.0 provides an analys is and interpretation of these SSTR data. 
3.0 SSTR EXPER IMENT IN THE TMI-2 REACTOR CAVITY

The general test plan for the SSTR experiment in the TMI-2 annular gap is summarized in Table 1. The SSTR dosimeters used in the TMI-2 annular gap consisted of $1.91-\mathrm{cm}$ diameter mica track recorders and asymptotically thick $(20.0127 \mathrm{~cm}){ }^{235} \mathrm{U}$ foil, $1.27 \times 1.27 \mathrm{~cm}$ square. Figure 1 provides the detailed configuration and assembly of these SSTR neutron dosimeters. In order to distinguish between the two mica SSTR in each dosimeter, the label of the mica SSTR adjacent to the cap was primed, whereas the label of the mica SSTR adjacent to the case was unprimed.

TABLE 1

IRRADIATION TEST PLAN

Experimental Category

Deployment

Type of Dosimeter

Radial Location

Vertical Location

Exposure Interval
Status

Two SSTR stringers: 17 SSTRs on each stringer

Fourteen 235U foil-mica SSTR (A1-covered) Three 235 foil-mica SSTR (Cd-covered)

Between reactor vessel and mirror insulation; midway between reactor coolant nozzles

From 4 feet above nozzles to the bottom of the flow distributor plate

Insertion: August 19, 1983

Removal: September 9, 1983

Two axial stringers were deployed in the annular gap with 17 SSTR dosimeters located on each stringer. Of the 17 SSTR dosimeters, 14 were bare (i.e, aluminum covered) and 3 were cadmium covered. The axial locations (elevations) of these SSTRs, which are shown in Figure 2, extend from the nozzles well above the core to the flow distributor plate well below the core. The region around the nozzles was of interest, since it has been speculated that some fuel debris might be lodged in the inlet or outlet nozzles. 

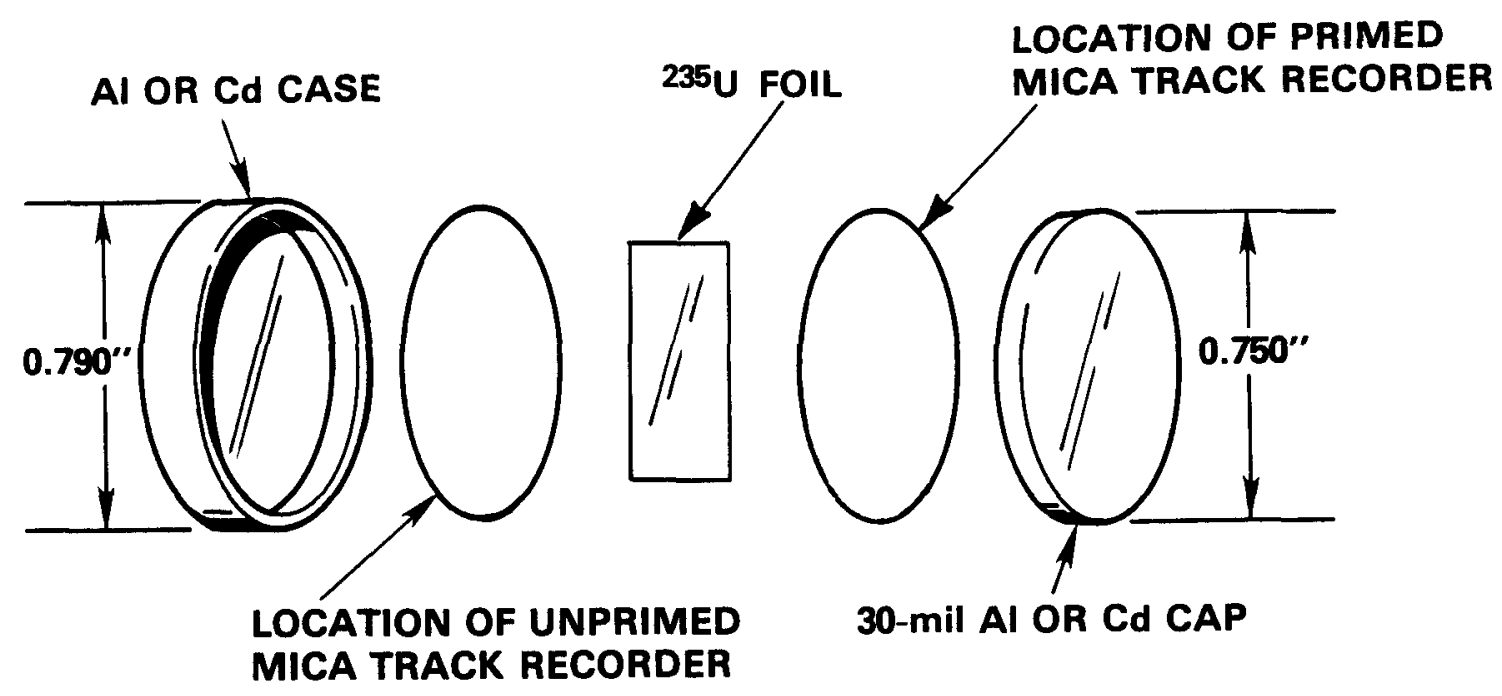

30-mil Al OR Cd CAP

HEDL 8408-037.15

FIGURE 1. Geometrical Details of the SSTR Neutron Dosimeter Used in the TMI-2 Annular Gap. Neg 8405948-1

The azimuthal locations of these two stringers are shown in Figure 3 . The east (E-SSTR) stringer and the west (W-SSTR) stringer were chosen near the SRMS. The count rate of the SRMs is roughly one order of magnitude higher than normal. The location of the SSTR stringers was chosen so that some insight into the origin of this high count rate might be provided by the SSTR dosimetry data.

These SSTR stringers were exposed in the TMI-2 annular gap for approximately 3 weeks from August 19, 1983 until September 9, 1983. After retrieval, they were shipped to the National Reactor Dosimetry Center at the Hanford Engineering Development Laboratory (HEDL) and processed. A preliminary appraisal of these SSTRs was completed within a week and revealed track densities that were sufficient to provide quantitative results. A more complete and quantitative analys is was then authorized, and this report provides the results of that analysis. 


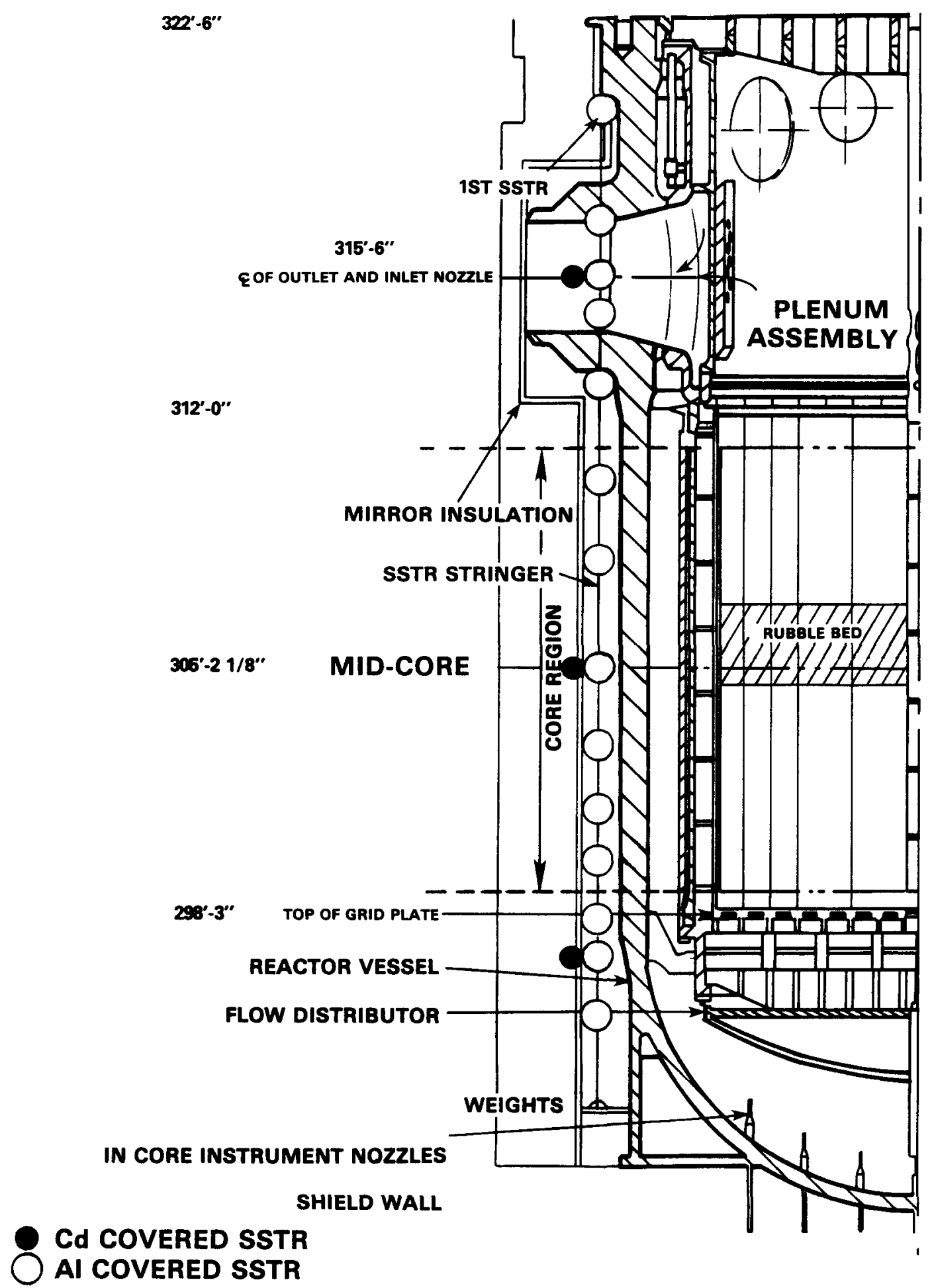

HEOL 8406-037.14

FIGURE 2. Deployment of SSTR Neutron Dosimeters on an Axial Stringer in the TMI-2 Annular Gap. Neg 8501182-2 


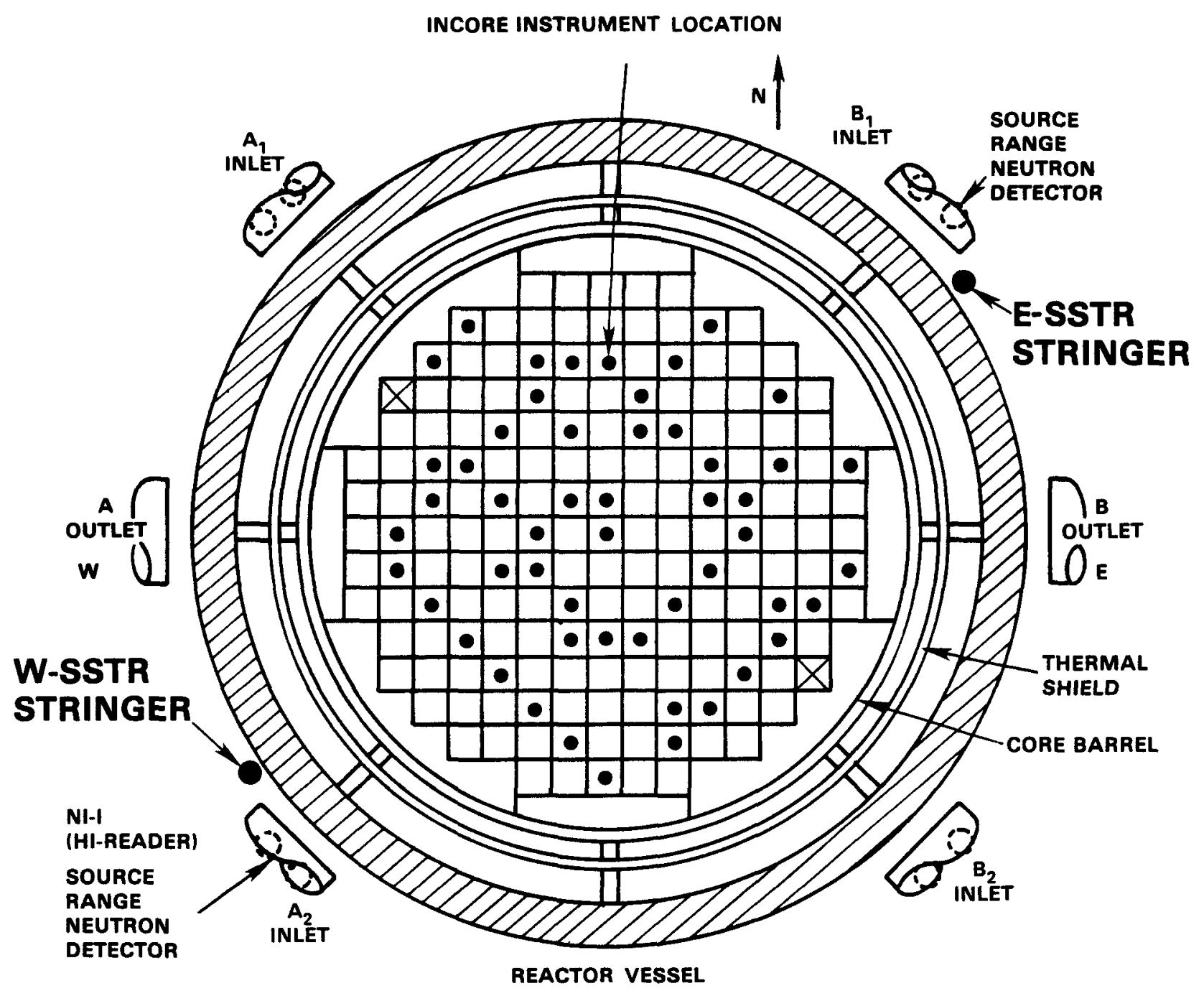

$\nabla=$ STARTUP SOURCES

HEDL 8406-037.7

FIGURE 3. Location of Two SSTR Stringers, East (E-SSTR) and West (W-SSTR), in the TMI-2 Annular Gap. 
4.0 SSTR EXPERIMENTAL RESULTS

Quantitative scans were conducted manually on both the primed and unprimed mica components of each ${ }^{235} U$ dosimeter (see Figure 1). The entire surface area of each $1.91 \mathrm{-cm}$ diameter mica SSTR was scanned by at least two observers. Scanning data for the E-SSTR and the W-SSTR are summarized in Tables 2 and 3 , respectively. These tabulated data represent an average of the results of different observors. The same data are shown graphically in Figures 4 and 5, where bare and Cd-covered track density are plotted, respectively. The cadmium ratio, i.e., the bare track density divided by the Cd-covered track density, is shown in Figure 6.

During containment entry for retrieval of the two stringers, it was noticed that the east stringer had slipped downwara from its original position by approximately $11 \mathrm{in.}$ Consequently, all SSTR elevations on the east stringer have been assumed to be 11 in. lower during the irradiation than originally planned.

SSTR data obtained from the east and west legs are entirely consistent and indicate an azimuthal symmetry. Both bare and Cd-covered track densities increase significantly with decreasing elevation. The increase in the bare track density with decreasing elevation is greater than the corresponding increase in the $\mathrm{Cd}$-covered track density. This difference can also be seen in Figure 6, where the cadmium ratio increases with decreasing elevation.

High accuracy and excellent observor objectivity have been attained in the inanual scanning of mica SSTR. $(7,8)$ It has been demonstrated that poisson statistics are applicable for manual scanning of SSTR, (9) and absolute accuracy of approximately $1 \%$ is attainable if care is exercised in all aspects of the experimental technique. (10) However, these established standards of precision and accuracy could not be attained with the mica SSTR exposed in the TMI-2 annular gap. Agreement between different observors scanning the same mica SSTR was often outside of statistics ana even observor reproducibility was not up to customary accuracy standards. It was also 
TABLE 2

TMI-2 ANNULAR GAP E-SSTR TRACK DENSITY* RESULTS

\begin{tabular}{|c|c|c|c|c|c|c|c|}
\hline ELEVATION & $\begin{array}{l}\text { UNPRIMED } \\
\text { SSTR }\end{array}$ & $\begin{array}{c}\text { PRIMED } \\
\text { SSTR } \\
\end{array}$ & $\frac{\text { UNPRIMED }}{\text { PRIMED }}$ & AVERAGE & $\begin{array}{c}\text { BARE } \\
\text { AVERAGE- } \\
\text { BACKGROUND** } \\
\end{array}$ & $\begin{array}{c}\text { CADMIUM } \\
\text { AVERAGE- } \\
\text { BACKGROUND*** } \\
\end{array}$ & $\frac{\text { BARE-Cd }}{C d}$ \\
\hline $318^{\prime}-7^{\prime \prime}$ & 36.8 & 39.5 & 0.93 & 38.2 & 34.6 & & \\
\hline $316^{\prime}-1^{\prime \prime}$ & 43.8 & 46.6 & 0.94 & 45.2 & 41.6 & & \\
\hline $314^{\prime}-7^{\prime \prime}$ & 53.6 & 73.2 & 0.73 & 63.4 & 59.8 & & \\
\hline $314^{\prime}-7^{\prime \prime} \quad(C d)$ & 18.4 & 23.7 & 0.78 & 21.1 & -- & 18.5 & 2.14 \\
\hline $313^{\prime}-7^{\prime \prime \prime}$ & 51.6 & 67.5 & 0.76 & 59.6 & 56.0 & . & \\
\hline $310^{\prime}-7^{\prime \prime}$ & 45.0 & 72.9 & 0.62 & 59.0 & 55.4 & & \\
\hline $308^{\prime}-7^{\prime \prime}$ & 63.2 & 70.3 & 0.90 & 66.8 & 63.2 & & \\
\hline $306^{\prime}-7^{\prime \prime}$ & 88.5 & 72.5 & 1.22 & 80.5 & 76.9 & & \\
\hline $304^{\prime}-7^{\prime \prime}$ & 97.3 & 86.3 & 1.13 & 91.8 & 88.2 & & 292 \\
\hline $304^{\prime}-7^{\prime \prime} \quad(C d)$ & 21.1 & 27.9 & 0.76 & 24.5 & -- & 21.9 & 2.92 \\
\hline $302^{\prime}-7^{\prime \prime}$ & 107.8 & 114.5 & 0.94 & 111.2 & 107.6 & & \\
\hline $300^{\prime}-7^{\prime \prime}$ & 67.6 & 82.2 & 0.82 & 74.9 & 71.3 & & \\
\hline $299^{\circ}-1^{\prime \prime}$ & 172.5 & 173.7 & 0.99 & 173.1 & 169.5 & & \\
\hline $297^{\prime}-7^{\prime \prime}$ & 237.6 & 228.5 & 1.04 & 233.1 & 229.5 & & \\
\hline $296^{\prime}-1^{\prime \prime}$ & 249.2 & 283.7 & 0.88 & 266.5 & 262.9 & & 342 \\
\hline $296^{\prime}-1^{\prime \prime} \quad(C d)$ & 58.4 & 64.2 & 0.91 & 61.3 & -- & 58.7 & 3.43 \\
\hline $294^{\prime}-7^{\prime \prime}$ & 341.3 & 286.0 & 1.19 & 313.7 & 310.1 & & \\
\hline
\end{tabular}

"TRACK DENSITY IN UNITS OF TRACKS $/ \mathrm{cm}^{2}$.

* BARE BACKGROUND = 3.6

***CADMIUM-COVERED BACKGROUND $=\mathbf{2} .6$. 
TABLE 3

TMI-2 ANNULAR GAP W-SSTR TRACK DENSITY* RESULTS

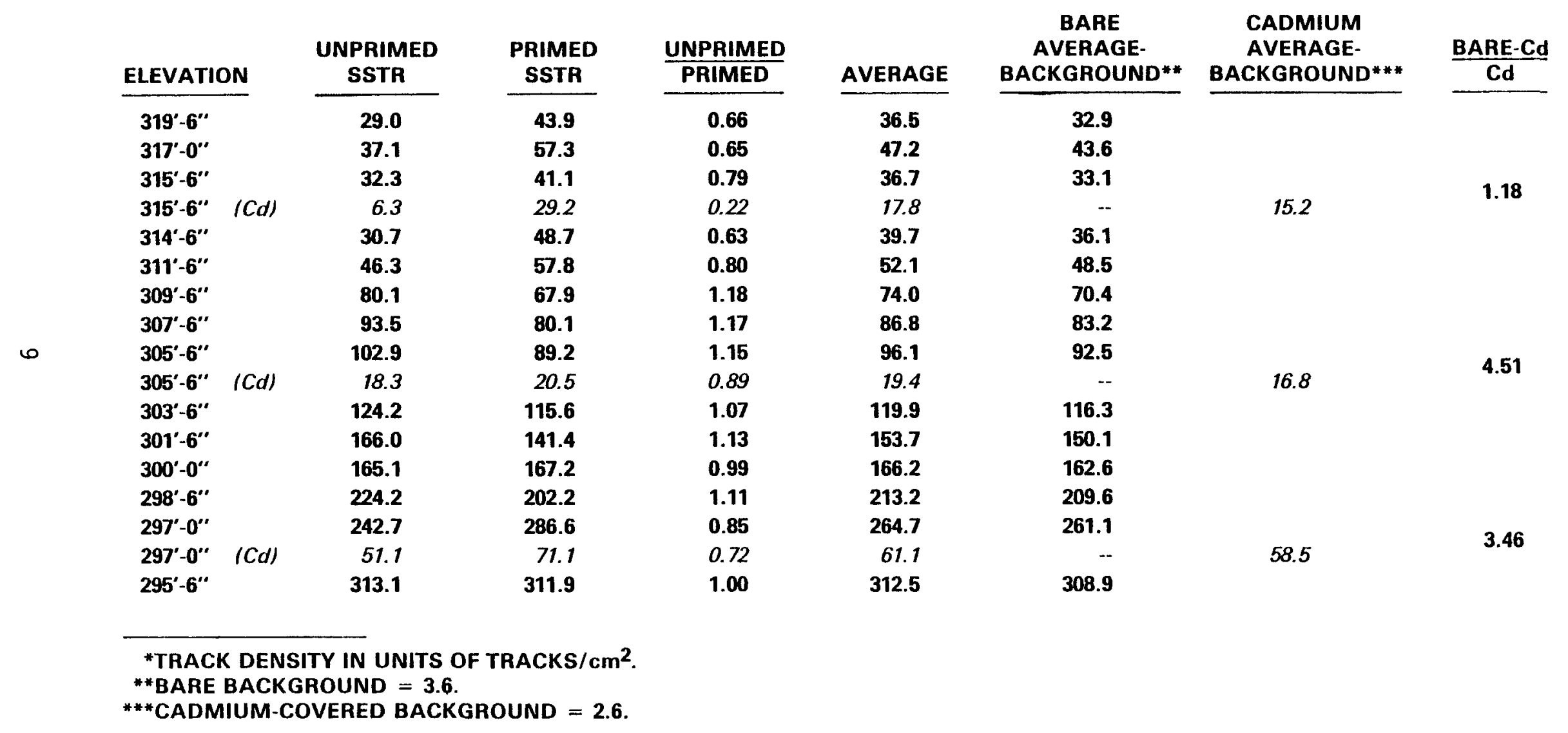




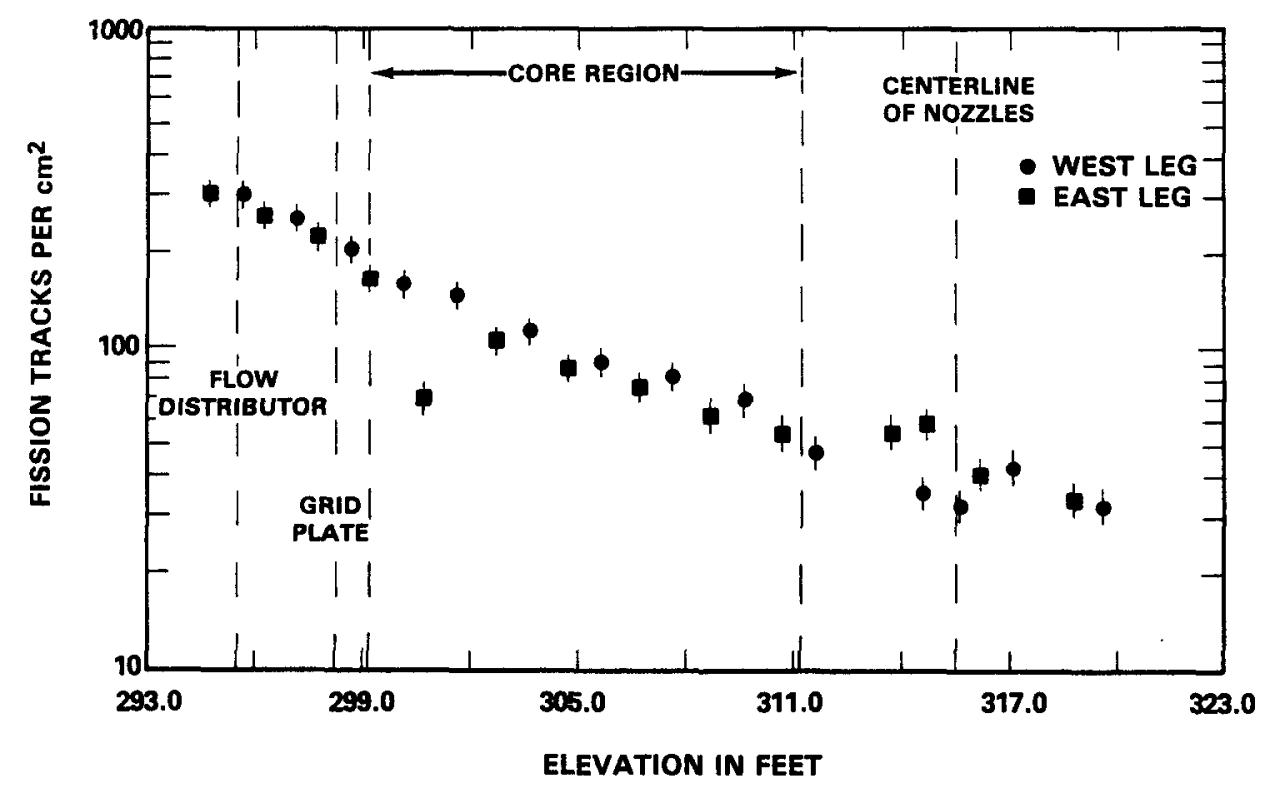

HEDL 30000007.4

FIGURE 4. Bare SSTR track Density as a Function of Elevation in the TMI-2 Annular Gap. Uncertainty because of track counting statistics is displayed at the 10 level. Neg 8505931-4

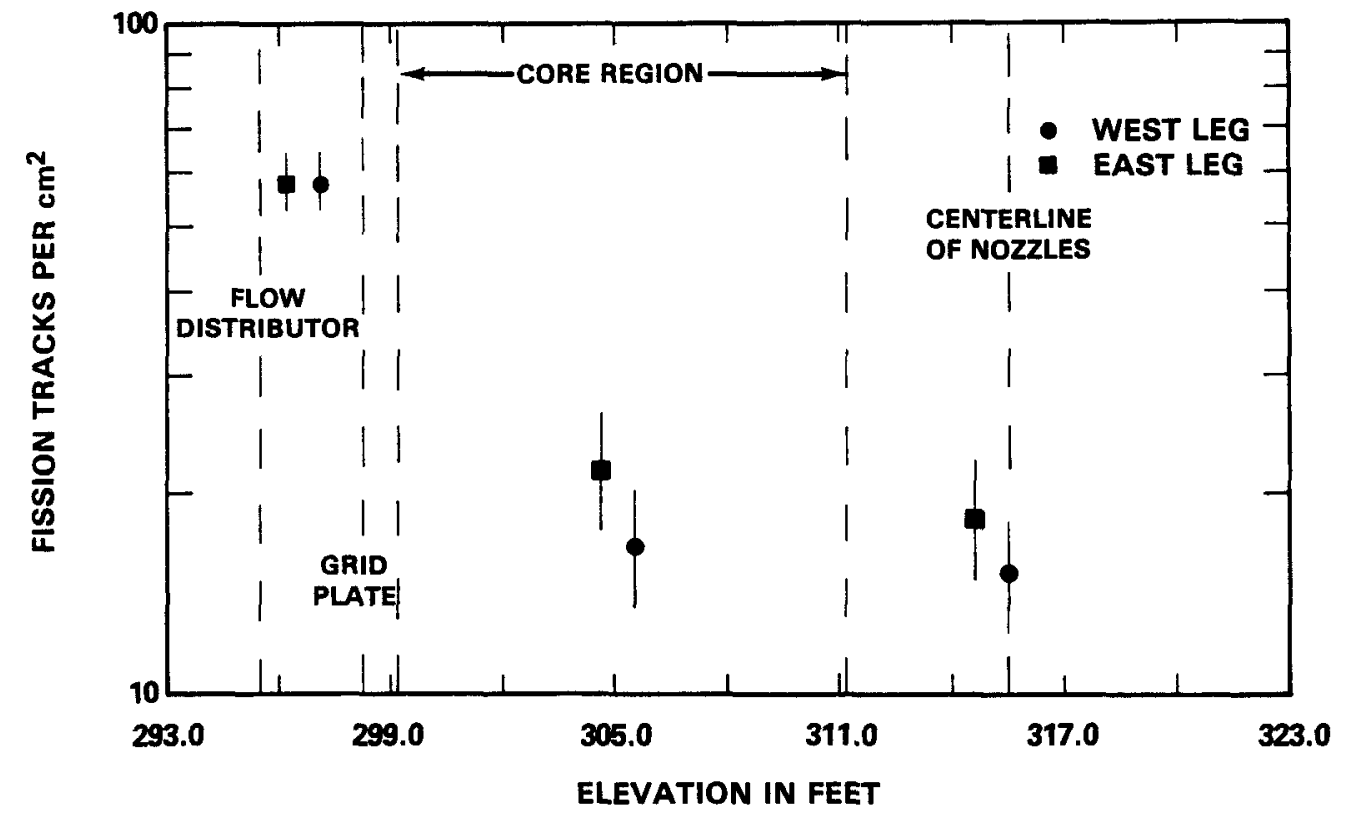

HEDL 8408-037.6

FIGURE 5. Cadmium-Covered SSTR Track Density as a Function of Elevation in the TMI-2 Annular Gap. Uncertainty because of track counting statistics is displayed at the 10 level. Neg 8505931-6 


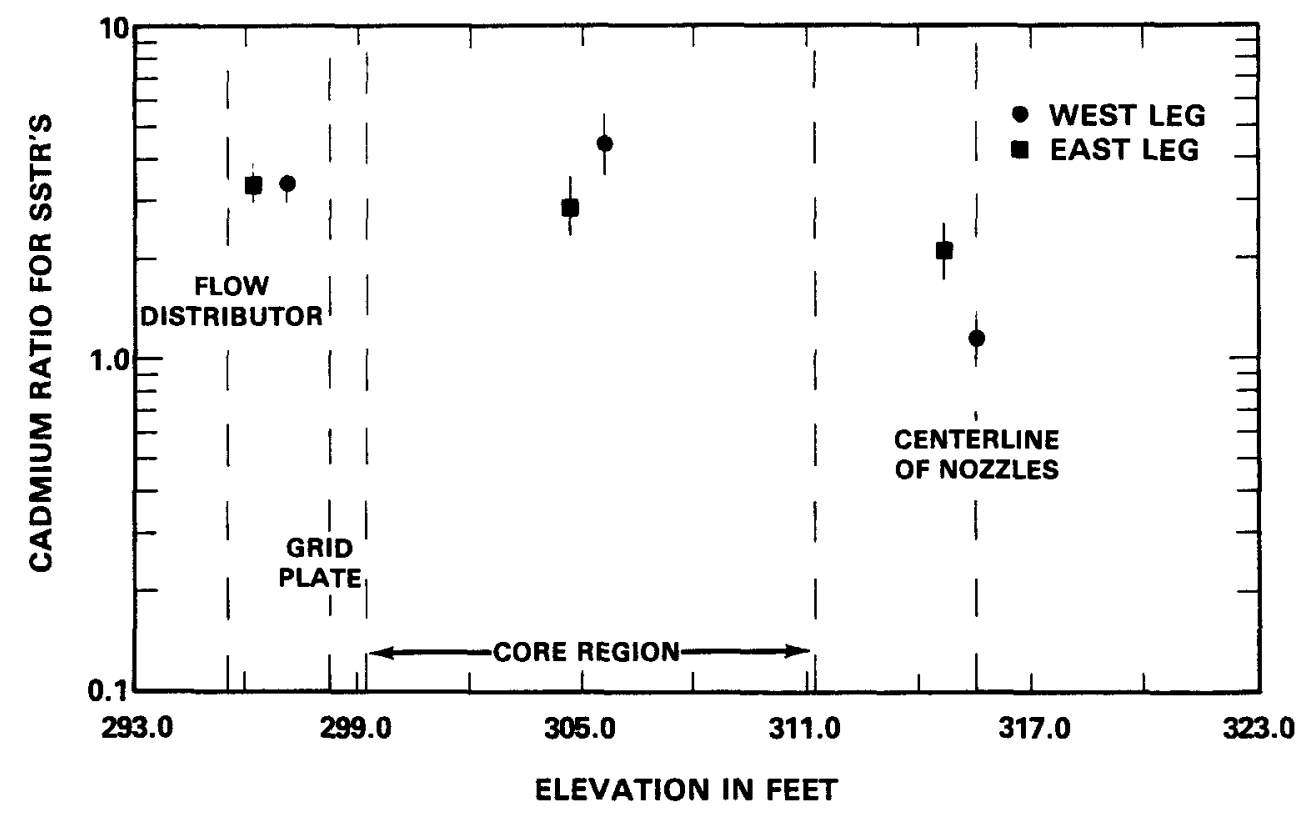

FIGURE 6. Cadmium Ratio as a Function of Elevation in the TMI-2 Annular Gap. Uncertainty because of track counting statistics is displayed at the lo level. Neg 8405931-5

realized that the unprimed and primed SSTR did not agree within statistics for many cases. As can be seen in Tables 2 and 3, the unprimed-to-primed ratio can differ significantly from unity and appears to vary systematically with elevation.

It was conjectured that observation of larger fission tracks could resolve these scanning problems. To this end, the mica SSTRs exposed in the TMI-2 annular gap were etched again to enlarge the observed fission tracks. However, the overall quality of the SSTR scanning data obtained after the second etch was essentially unchanged. Hence, it was concluded that these effects could not stem from observor bias, but actually did arise from exposure in the TMI-2 annular gap. The results reported in Tables 2 and 3, as well as those depicted in Figures 4 through 6 , represent average over all SSTR scanning data, which include scanning efforts after both the first etch and the subsequent second etch. 
5.0 ANALYSIS AND INTERPRETATION OF SSTR DATA

5.1 DETERMINATION OF ABSOLUTE THERMAL NEUTRON FLUX

Absolute thermal neutron fluxes have been determined from the TMI-2 annular gap SSTR data. The thermal neutron flux, $\phi_{t h}$, is given by the relation

$$
\phi_{t h}=\frac{\left(\rho_{B}-\rho_{C d}\right)}{\sigma_{t h} \cdot s_{\infty}^{-T}} \cdot C_{s},
$$

where:

$$
\begin{aligned}
\rho_{B}= & \text { Bare track density } \\
\rho_{C d}= & \text { Cd-covered track density } \\
\sigma_{t h}= & \text { Thermal average fission cross section of } 235 \mathrm{U} \\
& \left(\sigma_{t h}=(/ \pi / 2) \cdot 580 \mathrm{~b}=514.2 \mathrm{~b}\right) \\
T= & \text { Exposure interval }\left(T=1.81 \times 10^{6} \mathrm{~s}\right) \\
s_{\infty}= & \text { Asymptotic sensitivity of the } 235 \mathrm{U} \text { foil } \\
& \left(s_{\infty}=1.15 \times 1019 \text { atoms } / \mathrm{cm}^{2}\right) \\
C_{S}= & \text { Correction factor for neutron self-shielding. }
\end{aligned}
$$

Here the asymptotic sensitivity is the SSTR efficiency expressed in units of atoms per unit area. It is essentially the number of atoms per $\mathrm{cm}^{2}$ that can give rise to observable tracks at the surface of the mica SSTR after suitable etching. (9) Since the cutoff energy of the cadmium used for these SSTR measurements is roughiy $0.5 \mathrm{eV}$, the thermal neutron flux defined in Eq. (1) corresponds to all neutrons of energy less than approximately $0.5 \mathrm{eV}$.

In general, the self-shielding created by the presence of the ${ }^{235} \mathrm{U}$ foil depends on the angular distribution of the neutron flux. In absence of specific information on the angular flux distribution, the self-shielding correction factor for an isotropic flux distribution has been used. For 
isotropic neutron fields, one can show for SSTR dosimeters employing asymptotically thick foils that

$$
C_{s}=2 \cdot\left[1+E_{2}(\tau)\right]^{-1}
$$

where $E_{2}$ is the second order exponential integral given by

$$
E_{2}(\tau)=\int_{1}^{\infty} e^{-\tau x} / x^{2} d x
$$

The argument $\tau$ of this second order exponential integral is simply

$$
\tau=t \cdot \Sigma_{a},
$$

where $t$ is the foil thickness and $\Sigma_{a}$ is the macroscopic absorption cross section. For the present ${ }^{235} U$ foil, one has $\tau=0.4$, so that $E_{2}(0.4)=0.4$ and therefore, $c_{s}=1.43$ for isotropic neutron fields.

Table 4 displays the thermal neutron fluxes obtained by using these numeriCal values in Eq. (1) together with the track density data already given in Tables 2 and 3. Since the cd-covered track density was only available at three locations (see Figure 5), it was necessary to interpolate or extrapolate these Cd-covered data for use in Eq. (1) at other locations. The thermal flux derived from Eq. (1) in this manner represents a thermal neutron group below the cadmium cut-off energy, which is approximately $0.5 \mathrm{eV}$ for the cadmium covers used in these measurements.

The overall uncertainty in absolute thermal neutron flux varies with elevation from roughiy 40 percent $(10)$ at the top of each stringer down to about 20 percent $(1 \sigma)$ at the bottom of each stringer. Track counting statistics is the dominant contributor to experimental uncertainty at the top of the 
TABLE 4

ABSOLUTE THERMAL NEUTRON FLUXES IN THE TMI-2 REACTOR CAVITY

\begin{tabular}{|c|c|c|c|}
\hline \multicolumn{2}{|c|}{ East Leg Stringer } & \multicolumn{2}{|c|}{ West Leg Stringer } \\
\hline Elevation & $\phi \operatorname{th}^{\star}$ & Elevation & $\phi \operatorname{th}^{\star}$ \\
\hline $318^{\prime}-7 "$ & 2.3 & $319^{\prime}-6^{\prime \prime}$ & 2.5 \\
\hline $316^{\prime}-7^{\prime \prime}$ & 3.3 & $317^{\prime}-0^{\prime \prime}$ & 4.1 \\
\hline $314^{\prime}-7 "$ & 5.9 & $315^{\prime}-6^{\prime \prime}$ & 2.6 \\
\hline $313^{\prime}-7^{\prime \prime}$ & 5.4 & $314^{\prime}-6^{\prime \prime}$ & 3.0 \\
\hline $310^{\prime}-7 "$ & 5.2 & $311^{\prime}-6 "$ & 4.7 \\
\hline $308^{\prime}-7^{\prime \prime}$ & 6.3 & $309^{\prime}-6^{\prime \prime}$ & 7.8 \\
\hline $306^{\prime}-7 "$ & 7.9 & $307^{\prime}-6^{\prime \prime}$ & 9.5 \\
\hline $304^{\prime}-7 "$ & 9.5 & $305^{\prime}-6^{\prime \prime}$ & 10.9 \\
\hline $302^{\prime}-7 "$ & 11.5 & $303^{\prime}-6^{\prime \prime}$ & 13.8 \\
\hline $300^{\prime}-7 "$ & 5.6 & $301^{\prime}-6 "$ & 17.9 \\
\hline $299^{\prime}-7^{\prime \prime}$ & 18.3 & $300^{\prime}-0^{\prime \prime}$ & 18.7 \\
\hline $297^{\prime}-7 "$ & 25.7 & $298^{\prime}-6^{\prime \prime}$ & 23.7 \\
\hline (1" & 29.1 & $297^{\prime}-0^{\prime \prime}$ & 29.0 \\
\hline $294^{\prime}-7 "$ & 34.4 & $295^{\prime}-6^{\prime \prime}$ & 33.1 \\
\hline
\end{tabular}

*Thermal flux in units of $10^{-3}$ neutrons $/\left(\mathrm{cm}^{2} \cdot \mathrm{s}\right)$.

stringers where the flux and, hence, the track density are low. At the bottom of the stringers, the uncertainty in the self-shielding correction factor completely dominates. Application of the isotropic self-shielding correction factor introduces a substantial uncertainty component, which has been estimated to be approximately 20 percent (10). Assignment of such a large uncertainty component for the self-shielding correction stems from the fact that the neutron field in the TMI-2 annular gap is far from isotropic, as will be discussed in considerably greater detail below. 


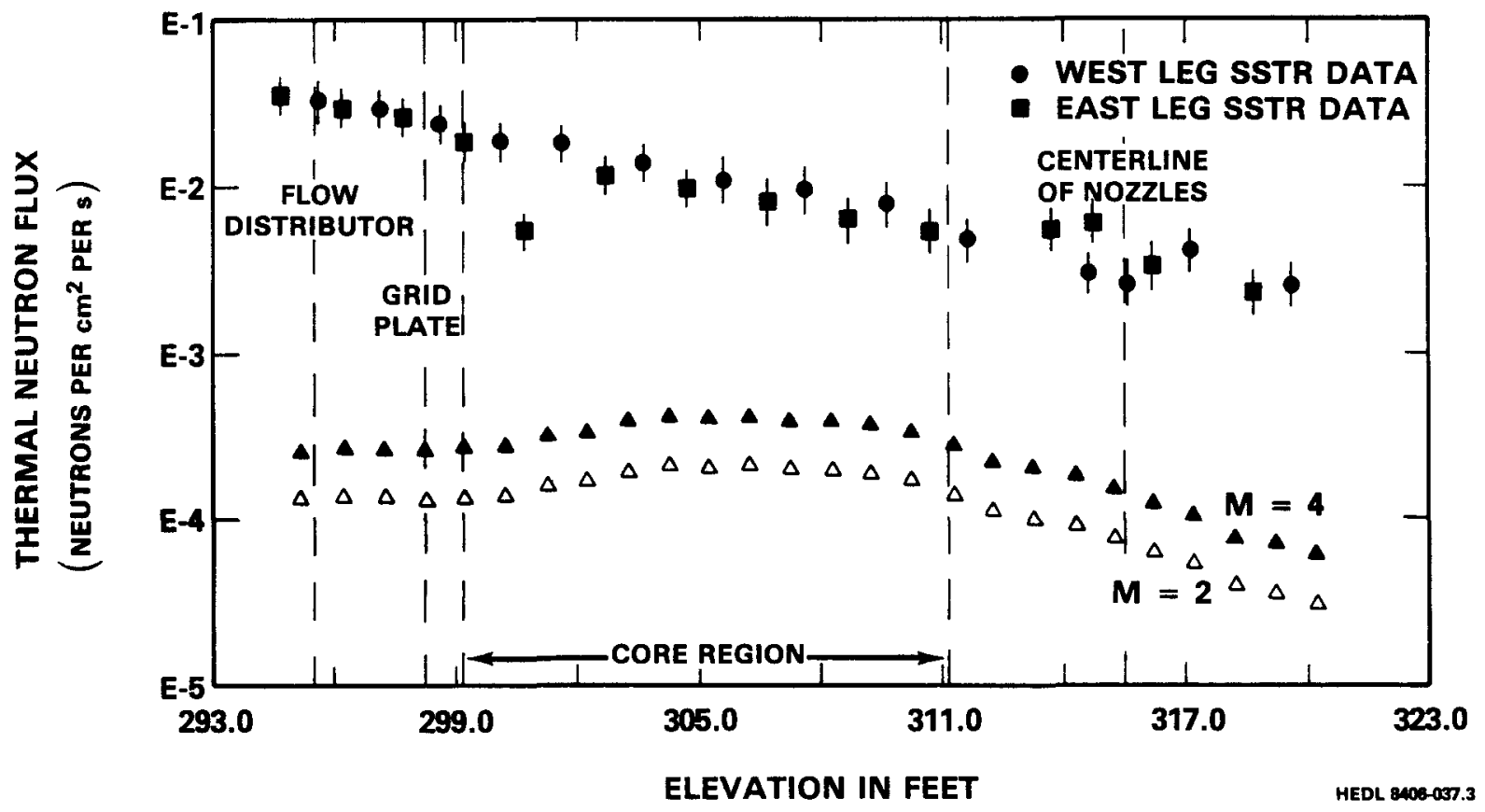

FIGURE 7. Thermal Neutron Fluxes in the TMI-2 Annular Gap. Overall experimental uncertainty is displayed at the 1o level. Neg 8501167-1

\subsection{NEUTRON STREAMING INTERPRETATION OF SSTR DATA}

Absolute thermal neutron fluxes obtained from these SSTR data are plotted in Figure 7 in comparison with the thermal flux anticipated for the TMI-2 reactor cavity. The curves, labeled $M=2$ and $M=4$, correspond to a core multiplication of 2 and 4 , respectively. These curves were obtained by scaling of radiometric dosimetry conducted in the ANO-1 reactor cavity, ${ }^{11,12)}$ a Babcock and Wilcox (B\&W) plant of similar design to TMI-2. The normal shutdown neutron multiplication for such a $B \& W$ plant is $M=12$. However, the high concentration of borated water and the redistribution of the core lower the estimated multiplication at TMI-2 to the approximate range: $2 Y_{M}<4$.

These TMI-2 annular gap results differ significantly in shape and magnitude from the anticipated thermal flux. The TMI-2 thermal flux intensity exceeds the anticipated intensity by roughly one order of magnitude at high elevations, and this difference grows with decreasing elevation to more than two orders of magnitude at the flow distributor elevation. In contrast with the 
axial symmetry expected about midplane, as observed in the ANO-1 radiometric dosimetry data, the SSTR data for TMI-2 are clearly asymmetric.

Consequentiy, the SSTR data reveal the existence of a neutron transport phenomenon that dominates the neutron intensity and that is not predicted by scaling measurements or calculations for a normal core configuration. Indeed, this very same phenomenon could be responsible for the variation arising in the unprimed-to-primed ratio, as well as the other scanning difficulties encountered with these SSTRs. In fact, one would expect an unprimed-to-primed ratio of unity in an isotropic neutron field. Since the $0.0127-\mathrm{cm}$ thick ${ }^{235} \mathrm{U}$ foil is highly absorbing for low energy neutrons, deviation of this ratio from unity could arise in anisotropic neutron fields because of attenuation through the foil. Given the exposure geometry used in the TMI-2 annular gap, an anisotropic neutron field could induce nonuniform track density in the mica SSTR. At the very low track densities produced here, non-uniformity of track density could explain the manual scanning difficulties that have been encountered.

All of these factors, in consort, provide strong evidence that a highly anisotropic neutron field exists in the TMI-2 annular gap. The sharp contrast in both magnitude and shape between the observed SSTR distribution and the anticipated axial distribution, which has already been presented in Figure 7, implies that the anisotropic neutron field is due to neutron streaming upward through the annular gap from the bottom of the reactor cavity. Hence, the neutron transport phenomenon that dominates the neutron intensity in the TMI-2 annular gap is neutron streaming from source neutrons located at the bottom of the reactor cavity.

The SSTR vertical profile of the neutron intensity is consistent with the presence of a significant amount of fuel debris, equivalent to several fuel assemblies or more, lying at the bottom of the reactor vessel. Neutrons from this quantity of fuel can pass essentially unmoderated out of the reactor vessel into the cavity beneath the vessel, where they are moderated within the concrete and stream upward through the annular space between the vessel and the biological shield. The reactor cavity, which is the region between the reactor pressure vessel and the biological shield, is shown in figure 8 . 


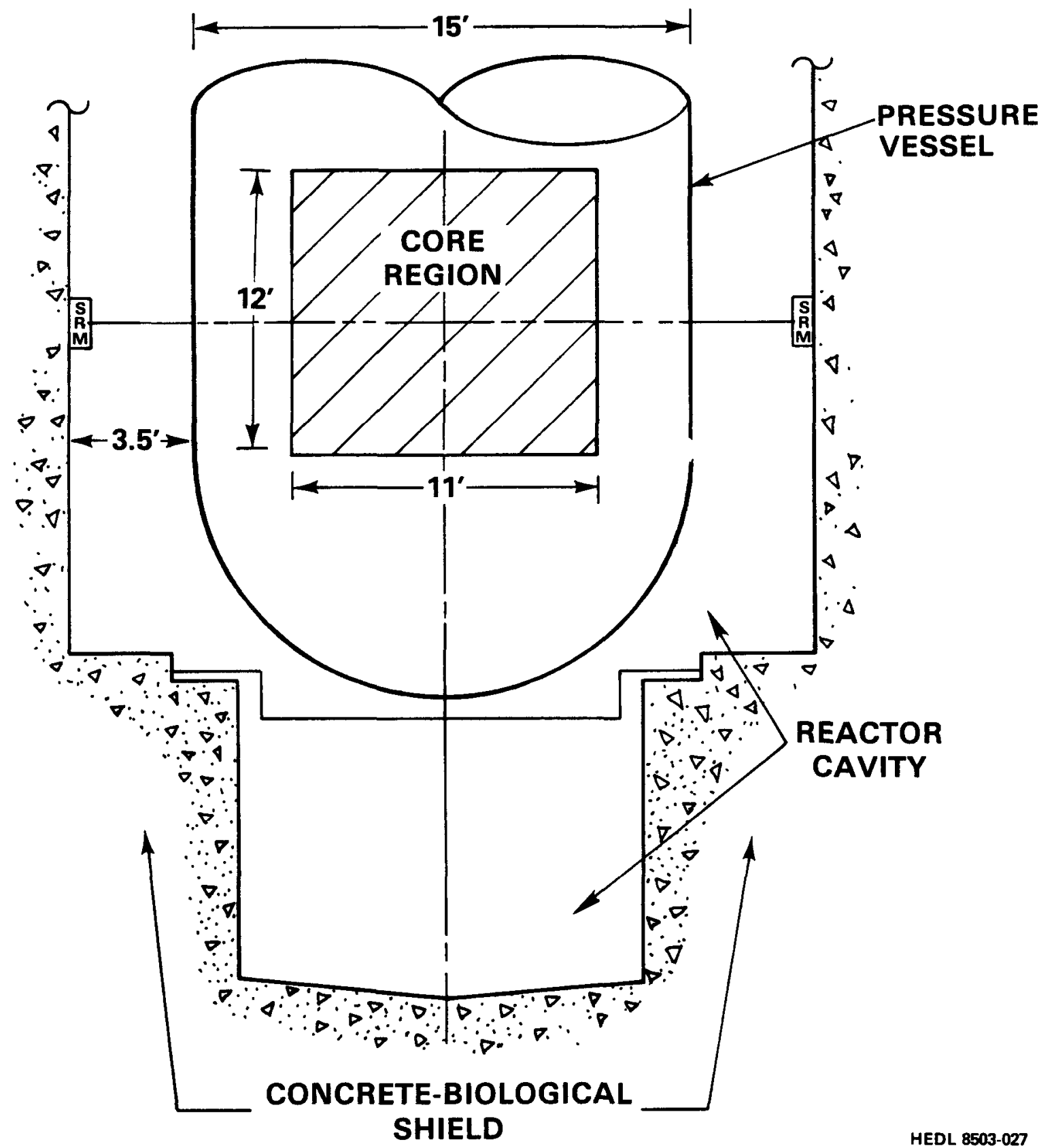

FIGURE 8. Axial Schematic of the TMI-2 Reactor Cavity. Neg 8501165-1 
Since neutron absorption cross sections generally increase with decreasing neutron energy, this neutron streaming model provides a qualitative explanation for the behavior of the cadmium ratio as a function of elevation. As already shown in Figure 6 , decrease of the cadmium ratio with increasing elevation can be explained by the fact that thermal neutrons streaming upward would possess a higher probability of absorption in the annular gap walls than would epithermal neutrons.

\subsection{LOWER BOUND ESTIMATE OF THE FUEL MASS AT THE BOTTOM OF THE TMI-2} REACTOR VESSEL

A lower bound for the quantity of fuel lying at the bottom of the reactor vessel can be estimated from earlier SSTR neutron dosimetry conducted inside the Demineralizer A cubicle. ${ }^{(3,4)}$ In these earlier efforts, the fuel content in Demineralizer A was determined from "room-return" analyses of the SSTR neutron dosimetry data in terms of follow-on calibration experiments. Consequentiy, these Demineralizer $A$ efforts provide a calibration factor that can be scaled to the reactor cavity observations. At the same time, one must account for the major differences in neutron transport between these two environments.

The Demineralizer A "room-return" calibration factor, $C_{F}$, can be expressed as

$$
C_{F}=M_{A} / \rho_{A} \text {, }
$$

where $M_{A}$ is the fuel content of Demineralizer $A$ and $\rho_{A}$ is the observed "roomreturn" track density in the Demineralizer A cubicle. From the SSTR neutron dosimetry work in the Demineralizer $A$ cubicle ${ }^{(3,4)}$, one has ${ }_{A}=5.0$ tracks/ $\mathrm{cm}^{2}$. For the value of $M_{A}$, one can use the average of two independent determinations, namely $1.3 \mathrm{~kg}$ from SSTR neutron dosimetry $(3,4)$ and $1.7 \mathrm{~kg}$ from continuous gamma-ray spectrometry. ${ }^{(2)}$ Consequently, $M_{A}=(1.3+1.7) / 2=$ $1.5 \mathrm{~kg}$. Therefore, $C_{F}=0.30 \mathrm{~kg} /\left(\operatorname{tracks} / \mathrm{cm}^{2}\right)$. 
Because of the very low track counting statistics as well as the general difficulties encountered in the Demineralizer A experiment, ${ }^{(2-6)}$ this value of the "room-return" calibration factor possesses very high experimental uncertainty. Actually, this uncertainty has been estimated to be roughly 50 percent $(1 \sigma)$, so that $C_{F}=0.30 \pm 0.15$ from the Demineralizer $A$ experiment. However, the follow-on work conducted to analyze the Demineralizer A experiment ${ }^{(3)}$ can be used to generate a more representative value of the "roomreturn" calibration factor, which is of considerably higher accuracy, namely 20 percent $(10)$. In contrast to the Demineralizer $A$ result, the follow-on calibration work yields $C_{F}=0.46 \pm 0.09$. While these two results are consistent within experimental uncertainty, the more accurate and representative value of $C_{F}$ obtained from the follow-on calibration work will be used to generate a lower bound estimate.

An estimate of the quantity of fuel that exists at the bottom of the reactor vessel, $M_{V}$, can be written in terms of this calibration factor as

$$
M_{V}=C_{F} \cdot o_{V} \cdot s_{1} \cdot s_{2} \cdot \cdot s_{n}
$$

where $\rho_{V}$ is the "room-return" track density in the void below the reactor vessel and $S_{1}, S_{2}, \ldots S_{n}$ are scale factors that account for the major differences in neutron transport between the Demineralizer $A$ and the reactor cavity environments. Table 5 summarizes the scale factors used in Eq. (6).

The "room-return" track density $\rho_{V}$ required in Eq. (6) is that attained in the void region below the reactor vessel. This region was obviously not accessible for SSTR measurements. However, a lower bound for $\rho_{V}$ can be obtained from the SSTR dosimetry data in the annular gap. On the basis of the shape of the SSTR vertical profile given in Figure 7 , one can conclude that $\rho_{V}$ must exceed the track density observed at the lowest stringer locations, which corresponds to the $294 \mathrm{ft}-7 \mathrm{in}$. and $295 \mathrm{ft}-6 \mathrm{in}$. elevations of the east and west legs, respectively. Consequently from Tables 2 and 3 , one can write

$$
o_{V} \approx 310 \text { tracks } / \mathrm{cm}^{2}
$$


TABLE 5

NEUTRON TRANSPORT SCALE FACTORS

Effect

Attenuation of Source Neutrons $\left(S_{1}\right)$

Absorption in Borated Water $\left(S_{2}\right)$

ธ
Demineralizer A

The demineralizer A tank possesses negligible wall thickness.

The demineralizer A tank was dry.

29 days

21 days
Comments

At the bottom of the reactor cavity, the pressure vessel is 5-3/16 in. thick steel.

The interior of the reactor vessel contains highly concentrated borated water.

source neutrons emitted in the direction of the borated water have a negligible probability of escape, so that $S_{2}=4 \pi / 2 \pi=2$.

$S_{3} \cong 29 / 21=1.38$ *This attenuation range has been obtained from extensive efforfs to characterize light water
reactor (LWR) pressure vessel (PV) radiation environments. (13) 
Using this lower bound estimate of $\mathrm{o}_{V}$ in $\mathrm{Eq} .(6)$, together with the scale factors given in Table 5 , yields

$$
M_{V} \gtrsim(0.46) \cdot(310) \cdot(4.9) \cdot(2) \cdot(1.38)
$$

or

$$
M_{V} \approx 1930 \mathrm{~kg}
$$

It is important to stress that the lowest possible value for the source neutron attenuation scale factor, i.e., $S_{1} \cong 4.9$, has been used in Eqs. (8a) and (8b) to ensure the generation of a lower bound for $\mathrm{M}_{V}$. This lower bound estimate corresponds to a fuel equivalent of at least four fuel assemblies lying at the bottom of the reactor vessel.

In generating this lower bound, a number of neutron transport effects have been regarded as refinements that could be ignored for the purpose of obtaining the initial estimate given above. These effects are:

1) Dependence of SSTR "room-return" signal on void geometry, volume, and wall composition. .

2) Attenuation of source neutrons within the fuel debris and borated water at the bottom of the reactor vessel.

3) Neutron multiplication within the fuel debris at the bottom of the reactor vessel.

Should more accurate lower bound estimates be desired, the above effects would obviously need to be taken into account. However, any combined effect 
of these three refinements is expected to be small relative to the conservatism used in the generation of the present lower bound estimate and as a consequence the major conclusions drawn from these efforts remain unchanged.

Although it is nighly improbable, it is still possible that the observed SSTR signal could be due to the TMI-2 startup neutron sources, which could have somehow been transported to the bottom of the reactor vessel from their original miaplane locations (see Figure 3 ). The TMI-2 startup sources are the so-called $A B C$ type, i.e., a mixture of americium, beryllium and curium. Because of the ${ }^{242} \mathrm{Cm}$ isotope decay ( 163 day half-life), these sources are now essentially $\mathrm{Am}-\mathrm{Be}(\alpha, n)$ neutron sources. The estimated emission rate of each of these sources is roughly $6 \times 10^{6} \mathrm{n} / \mathrm{s}$. Since the neutron emission rate of TMI-2 fuel is approximately $300 \mathrm{n} /\left(\mathrm{s}{ }^{\circ} \mathrm{kg}\right)$, each of these sources possesses an emission rate equivalent to that produced by 20 tonnes of fuel.

Consequentiy, these startup sources possess sufficient intensity to explain the observed SSTR data, provided they nave reached the bottom of the reactor vessel and remain intact. However, these sources are encapsulated in a 304 stainless steel tube possessing the following dimensions: $7 / 32$-in. outer diameter, $18 \mathrm{in.}$ long, and 0.020-in. wall thickness. Startup sources are lowered into shroud tube assemblies in the core. The shroua tube assembly is essentially another welded 304 stainless steel tube designed to accept the 7/32-in. source tube. These shroud tube assemblies are located at the peripheral positions shown in Figure 3. The design, fabrication, and location of these startup sources make it extremely unlikely for them to have moved, let alone reached the bottom of the reactor vessel.

Finally, analysis of these SSTR data shows that the count rate of the SRMs, which are located near midplane in the reactor cavity, should be considerably higher than normal. It is recognized that the existence of significant neutron streaming must be taken into account for proper interpretation of SRM data in TMI-2 recovery operations. 
The support and exchange of ideas with government agencies, industrial participants, and advisory groups associated with TMI-2 recovery is acknowledged; notably DOE, EPRI, NRC, GPU, RHO, and the Technical Assistance and Advisory Group (TAAG) Committee for TMI-2 recovery. The support and guidance of WHC management is appreciated.

S. V. Rao, J. Greenborg, and V. R. Fricke were instrumental in the planning and conduct of this experiment. We are grateful to J. 0 . Henrie for discussions and review of the TMI-2 reactor system. The dedication to track scanning by P. A. Ombrellaro is also acknowledged. 
1. R. Gold, F. H. Ruddy, J. H. Roberts, C. C. Preston, J. A. Ulseth, W. N. McElroy, F. J. Leitz, B. R. Hayward and F. A. Schmittroth, "Application of Solid-State Track Recorder Neutron Dosimetry for Three-Mile Island Unit-2 Reactor Recovery," Nucl. Tracks 7, pp. 13-30, 1983.

2. J. P. McNeece, B. J. Kaiser, R. Gold and W. W. Jenkins, Fuel Assessment of the Three-Mile Island Unit-2 Makeup Demineralizers by Compton Recoil Continuous Gamma-Ray Spectrometry, HEDL-7285, Hanford Engineering Development Laboratory, Richland, WA, March 1983.

3. F. H. Ruddy, J. H. Roberts, R. Gold, C. C. Preston and J. A. Ulseth, Solid-State Track Recorder Neutron Dosimetry Measurements for Fuel Debris Location in the Three-Mile Is land Unit-2 Makeup and Purification Demineralizer, HEDL-SA-2834, Hanford Engineering Development Laboratory, Richland, WA, August 1983.

4. F. H. Ruddy, J. H. Roberts, R. Gold and C. C. Preston, "Applications of Solid-State Track Recorder Neutron Dosimetry for Fuel Debris Location in the Three-Mile Island Unit-2 Makeup and Purification Demineralizers," 12th International Conference on Solid-State Nuclear Track Detectors, Acapulco, Mexico, September 4-10, 1983.

5. R. Gold, J. H. Roberts, J. P. McNeece, B. J. Kaiser, F. H. Ruddy, C. C. Preston, J. A. Ulseth and W. N. McElroy, "Fuel Debris Assessment for Three-Mile Island Unit-2 (TMI-2) Reactor Recovery by Gamma-Ray and Neutron Dosimetry," 6th International Conference on Nondestructive Evaluation in the Nuclear Industry, Zurich, Switzerland, November 27December 2, 1983.

6. R. Gold, J. H. Roberts, F. H. Ruddy, C. C. Preston, J. P. McNeece, B. J. Kaiser and W. N. McElroy, "Characterization of Fuel Distributions in the Three-Mile Island Unit-2 (TMI-2) Reactor System by Neutron and Gamma-Ray Dosimetry," HEDL-SA-3063, 5th International ASTM-EURATOM Symposium on Reactor Dosimetry, Geesthacht, Federal Republic of Germany, September 24-28, 1984.

7. J. H. Roberts, R. Gold and F. H. Ruddy, "Optical Efficiency and Observer Objectivity for Fission Track Counting in Muscovite SolidState Track Recorders," Solid-State Nuclear Track Detectors, Proc. of the 11th International Conference on Solid-State Nuclear Track Detectors, Bristol (1981), Pergamon Press, Oxford, UK, p. 887, 1982.

8. J. H. Roberts, F. H. Ruddy and R. Gold, "Optical Efficiency for Fission Track Counting in Muscovite Solid State Track Recorders," 12th International Conference on Solid-State Nuclear Track Detectors, Acapulco, Mexico, September 4-10, T983. 
9. R. Gold, R. J. Armani and J. H. Roberts, "Absolute Fission Rate Measurements with Solid-State Track Recorders," Nucl. Sci. Eng. 34, 13, 1968.

10. R. Gold, "Critical Requirements of the SSTR Method," 1st International ASTM-EURATOM Symposium on Reactor Dosimetry, Petten, Netherlands, September 22-26, 1975, EUR 5667, Part II, p 175, 1977.

11. C. 0. Cogburn, J. B. Williams and N. Tsoulfanidis, "Pressure Vessel Dosimetry at U.S. PWR Plants," 5th International ASTM-EURATOM Symposium on Reactor Dosimetry, Geesthacht, Federal Republic of Germany, September 24-28, 1984.

12. T. H. Newton Jr, C. O. Coburn and J. G. Williams, "Use of Stainless Steel Flux Monitors in Pressure Vessel Surveillance," 5th International ASTM-EURATOM Symposium on Reactor Dosimetry, Geesthacht, Federal Republic of Germany, September 24-28, 1984.

13. W. N. MCElroy et a1., LWR PV-SDIP: PCA Experiments and Blind Test, NUREG/CR-1861, HEDL-TME 80-87, Nuclear Regulatory Commission, Washington, DC, JuTy 1981 . 

DISTRIBUTION

DOE -RL/AMD (2)

Waste Management Division

JD White, Director

FED $/ 610$

M. Dayani, Prog Engineer FED/609

DOE-RL/AME

Breeder Technology Division

KR Absher, Chief

FED $/ 210$

DOE-Idaho Operations Office

TMI Technical Integration Office 550 Second Street

Idaho Falls, ID 83401

WW Bixby

EG\&G-Idaho, Inc (8)

Technical Integration office

P.0. Box 88

Middletown, PA 17057

GJ Quinn (7)

HM Burton $\frac{\text { Oak Ridge National Laboratory }}{\text { P.0. Box } X}$

Oak Ridge, TN 37830

WD Bond

Pennsylvania State University

Shavertown $\mathrm{Br}$

Wi lkes-Barre, PA 18708

B. Bandini

AJ Baratta

Rockwell Hanford Operations

North American Space Operations

P.0. Box 800

Richland, WA 99352

J0 Henrie

University of Arkansas (3)

Dept of Mechanical Engineering

Fayetteville, AR 72701

CO Cogburn

TH Newton

JG Williams

HEDL (44)

DG Doran

EA Evans

$R$. Gold (20)

BR Hayward

VP Kelly

NE Kenny

RL Knecht

MK Korenko

EP Lippincott

MK Mahaffey

WN MCEl roy
W/A-57

$W / C-23$

$W / C-39$

$W / C-44$

$W / C-86$

$W / C-115$

W/A-40

$W / C-27$

$W / C-39$

$W / B-12$

$W / C-39$
JP McNeece

WJ McShane

CC Preston

JH Roberts

FH Ruddy

FA Schmittroth

WF Sheely

KG Toyoda

HH Yoshikawa

Central Files

Documentation
W/A-56

W/B-1 12

$W / C-39$

$W / C-39$

$W / C-39$

W/A -4

$W / C-44$

$W / B-11$

$W / C-44$

$W / C-110$

$W / C-123$

Distr-1 
